\title{
TWO DIFFERENT TYPES OF PHOTOCHEMISTRY IN PHYCOERYTHROCYANIN $\alpha$-SUBUNIT*
}

\author{
QIANG Hong†, KaI-HoNG ZhaO AND Hugo ScheER $\ddagger$ \\ Botanisches Institut der Universität München, Menzinger Str. 67, D-80638 München 19, Germany
}

(Received 18 February 1993; accepted 13 July 1993)

\begin{abstract}
The photochemical activities of phycoerythrocyanin $\alpha$-subunits from Mastigocladus laminosus separated by isoelectric focusing were tested by irradiating at 500,550, 577 and $600 \mathrm{~nm}$. Two types of photoreversible photochromic responses have been characterized by absorption and absorption difference spectroscopy. Type $I$ is the well-known absorption shift from 571 to $506 \mathrm{~nm}$. Type II is a new response characterized by a line-broadening of the $570 \mathrm{~nm}$ absorption.
\end{abstract}

\section{INTRODUCTION}

Phycoerythrocyanin (PEC) $\$$ shows, unlike other phycobiliproteins, ${ }^{\prime}$ a photoreversible photochromism reminiscent of that of the plant photoreceptor phytochrome, but with orange/green rather than red/far red action spectra. ${ }^{2-8}$ The photochemical activity is due to the phycoviolobilin chromophore ( $\lambda_{\max } \approx 570 \mathrm{~nm}$ as isolated) located on the $\alpha$-subunit. ${ }^{9,10}$ Upon irradiation with orange light, a new absorption arises at $\approx 500 \mathrm{~nm}$ (P506), which is converted back reversibly to the $570 \mathrm{~nm}$ form (P571) upon irradiation with green light. There are several lines of evidence indicating that this photochemical response involves, as in the case of phytochrome, a reversible $\mathrm{Z} / \mathrm{E}$-isomerization at the double bond between rings $C$ and $D$ of the linear tetrapyrrole. ${ }^{5}$

Phycoerythrocyanin is commonly considered an antenna pigment, located together with phycocyanin and allophycocyanin in the phycobilisomes of certain cyanobacteria. ${ }^{11-13}$ There is presently no obvious physiological function for its photochromic behavior, although an involvement of PEC in photomorphogenetic responses of cyanobacteria cannot be ruled out. ${ }^{14,15}$ Even so, it represents an interesting case with a transitory behavior between that of the highly fluorescent but photochemically inactive phycobiliproteins, and the photochemically active phytochrome. ${ }^{16}$

In previous investigations of $\mathrm{PEC}$, large quantitative variations in the photochemistry of PEC and its $\alpha$-subunit were noticed, which are (among others) related to the aggregation state $^{2}$ and to the status of SH-groups located on the same subunit. ${ }^{17}$ The results presented here show that there exist also qualitative variations in the photochemical signal, and that (at least) two different reactivities are involved in the reversible photochemistry of the PEC $\alpha$-subunit.

*Dedicated to Prof. Dr. Wolfhart Rüdiger on the occasion of his 60 th birthday.

$†$ Present address: Center for Photomolecular Sciences, Imperial College, Prince Consort Road, London SW7 2BB, United Kingdom $\ddagger$ To whom correspondence should be addressed.

\$Abbreviations: $\mathrm{PEC}$, phycoerythrocyanin; $\mathrm{P}_{\mathrm{r}}$ and $\mathrm{P}_{\mathrm{fr}}$, phytochrome in the red and far-red absorbing form respectively; $\Delta \Delta \mathrm{A}$, difference amplitude of the light-induced absorption differences (see Materials and Methods section).

\section{MATERIALS AND METHODS}

Phycoerythrocyanin and its subunits were isolated from Mastigocladus laminosus as before. ${ }^{2.12}$

Absorption spectra were recorded in a lambda 2 spectrophotometer (Perkin-Elmer). Irradiations were done with a cold-light source (model 150, Volpi) equipped with fiber optics and suitable interference filters ( $10 \mathrm{~nm}$ bandwidth). The orange/green response ( 577 and $500 \mathrm{~nm}$ filters, respectively) was quantified in $\Delta \Delta \mathrm{A}_{1}$ units. It corresponds (as the $\Delta \Delta \mathrm{A}$ used before ${ }^{2}$ ) to the amplitude difference (maximum minus minimum) of the light-induced difference spectrum with extrema at $\approx 506$ and $\approx 571 \mathrm{~nm}$ (Fig. $1 \mathrm{~A}$ ), divided by the maximum absorption of the $570 \mathrm{~nm}$ form. The type II photochemistry (see text) was defined similarly by $\Delta \Delta \mathrm{A}_{\mathrm{II}}$. It corresponds to the amplitude difference (maximum minus minimum) of the light-induced difference spectrum with extrema at $\approx 595$ and $\approx 571 \mathrm{~nm}$ (Figs. IB,2), divided by the maximum absorption of the $570 \mathrm{~nm}$ form.

\section{RESULTS}

Several separations of PEC under apparently the same conditions yielded preparations of the PEC $\alpha$-subunit with rather different photochemical activities. The orange/red response (measured in $\Delta \Delta \mathrm{A}_{1}$ units ${ }^{2}$ ) varied between $12 \%$ and $92 \%$, and was generally on the high side. These variations are even more extreme than the reported values of $38 \%^{2}$ and $50 \%{ }^{4}$ and are mainly related to the status of SH-groups. ${ }^{17}$

The variations in photochemical activity of the $\alpha$-PEC samples of different photochemistry were accompanied by a shift in the absorption maximum of the red-absorbing form (enriched after $500 \mathrm{~nm}$ irradiation) from 561 (lowest) to 566 $\mathrm{nm}$ (highest photochemistry). Published spectra also follow this correlation: Siebzehnrübl et al. ${ }^{2}$ report $\lambda_{\max }=562 \mathrm{~nm}$ for a sample with $\Delta \Delta \mathrm{A}_{1}=38 \%$, and Kufer and Björn ${ }^{4} \lambda_{\max }$ $=564 \mathrm{~nm}$ for a sample with $\Delta \Delta \mathrm{A}_{1}=50 \%$. Furthermore, the low photochemistry sample showed a broader absorption and a less obvious shoulder after irradiation at $500 \mathrm{~nm}$ than the high photochemistry one (Figs. 1 and 2).

The difference spectra showed even more distinct changes, depending on the irradiation program. After subsequent irradiations at 500 and $570 \mathrm{~nm}$, the difference spectra of highphotochemistry samples were always dominated by the wellknown s-shaped type I signal (Fig. 1A). A rather different signal which has a w-shape typical for line broadening and a much smaller amplitude, was most clearly seen after subsequent irradiations at 577 and $600 \mathrm{~nm}$ (Fig. 1B). To distin- 
guish it from the classical type I response, it shall be called type II response. For quantifying this response, we define the $\Delta \Delta \mathrm{A}_{1 \mathrm{II}}$ as for the type I response, but with the extrema at $\approx 570$ and $\approx 595$ as the reference wavelengths (see Materials and Methods).

The type II response was more pronounced in the lowphotochemistry samples. Subsequent irradiations with 500 and $600 \mathrm{~nm}$ light resulted in a low amplitude $\left(\Delta \Delta \mathrm{A}_{\mathrm{I}} \approx 3.8 \%\right)$, somewhat distorted type I-signal $\left(\lambda_{\max } \approx 500\right.$ and $570 \mathrm{~nm}$, Fig. 2). Subsequent irradiations at other wavelength pairs $(577 / 600$ or $500 / 577)$ resulted, in contrast, mainly in w-shaped absorption differences characteristic of the type II response (Fig. 2), with $\Delta \Delta \mathrm{A}_{\text {II }}$ values $>10 \%$. Obviously, both signals are present in all samples, but the relatively small $\mathrm{w}$-shaped one is prominent only when the "classical" photochemistry of PEC is low, either by internal factors ${ }^{17}$ or by external ones (viz. the irradiation program).

\section{DISCUSSION}

The photochemistry of PEC $\alpha$-subunit was discovered by G.S. Björn ${ }^{3}$ during the search for cyanobacterial photochromic pigments (phycochromes) and has since been studied in considerable detail. ${ }^{2-8,17}$ Irrespective of quantitative variations, ${ }^{17}$ this phototransformation of the form absorbing at $\approx 570 \mathrm{~nm}$ (P571) to that absorbing at $\approx 500 \mathrm{~nm}$ (P506), is characterized by (i) a red shift of the long-wavelength absorption, (ii) a decrease in the near-UV absorption, ${ }^{16}$ (iii) a drop in fluorescence by a factor $\geq 5^{5}$, (iv) a quantum yield of $10 \%,{ }^{7}(v)$ an inversion of the circular dichroism signal, ${ }^{5}$ and (vi) only minor changes in the linear dichroism. ${ }^{8}$ Many of these features are similar to the ones observed during the phytochrome photoconversion from $P_{r}$ to $P_{f r}$. Since the phytochrome conversion involves most likely a Z-E isomerization of the chromophore at the 15,16-double bond between rings $\mathrm{C}$ and $\mathrm{D},{ }^{16}$ a similar isomerization has been suggested to occur during this type I photochemistry in the $\alpha-84$ phycoviolobilin chromophore of PEC. 5.77 The two distinct differences between the photochemistry of both pigments are also compatible with this interpretation: The absorption of the Z-isomer is bathochromically shifted in phytochrome and hypsochromically shifted in $\alpha-\mathrm{PEC}$, but it has been realized (albeit not understood on a molecular basis) for a long time that the bathochromic shift in phytochrome is unusual, whereas the hypsochromic shift is common for $15 \mathrm{Z}-15 \mathrm{E}$ isomerizations in bile pigments. ${ }^{18}$ The other difference is the small (apparent) reorientation of the chromophore in PEC, as determined by linear dichroism of the immobilized biliproteins. ${ }^{8}$ However, the change in orientation of the transition moment depends on many factors including the rigidity of the apoprotein, which can be very different for the two pigments, and the chromophore structure, whose $\pi$-system is considerably shorter in PEC than in phytochrome.

The molecular origin of the type II photochemistry described in this communication is presently unknown. Currently, we are investigating three possibilities: The first one is a $\mathrm{Z} / \mathrm{E}$-isomerization at the methine bridge between rings $B$ and $C$. Although such isomers are unstable at ambient temperatures in solution, ${ }^{88.19}$ they might be stabilized by the protein. The second possibility is a $\mathrm{Z} / \mathrm{E}$-isomerization at the methine bridge between rings $\mathrm{C}$ and $\mathrm{D}$, e.g. the same process
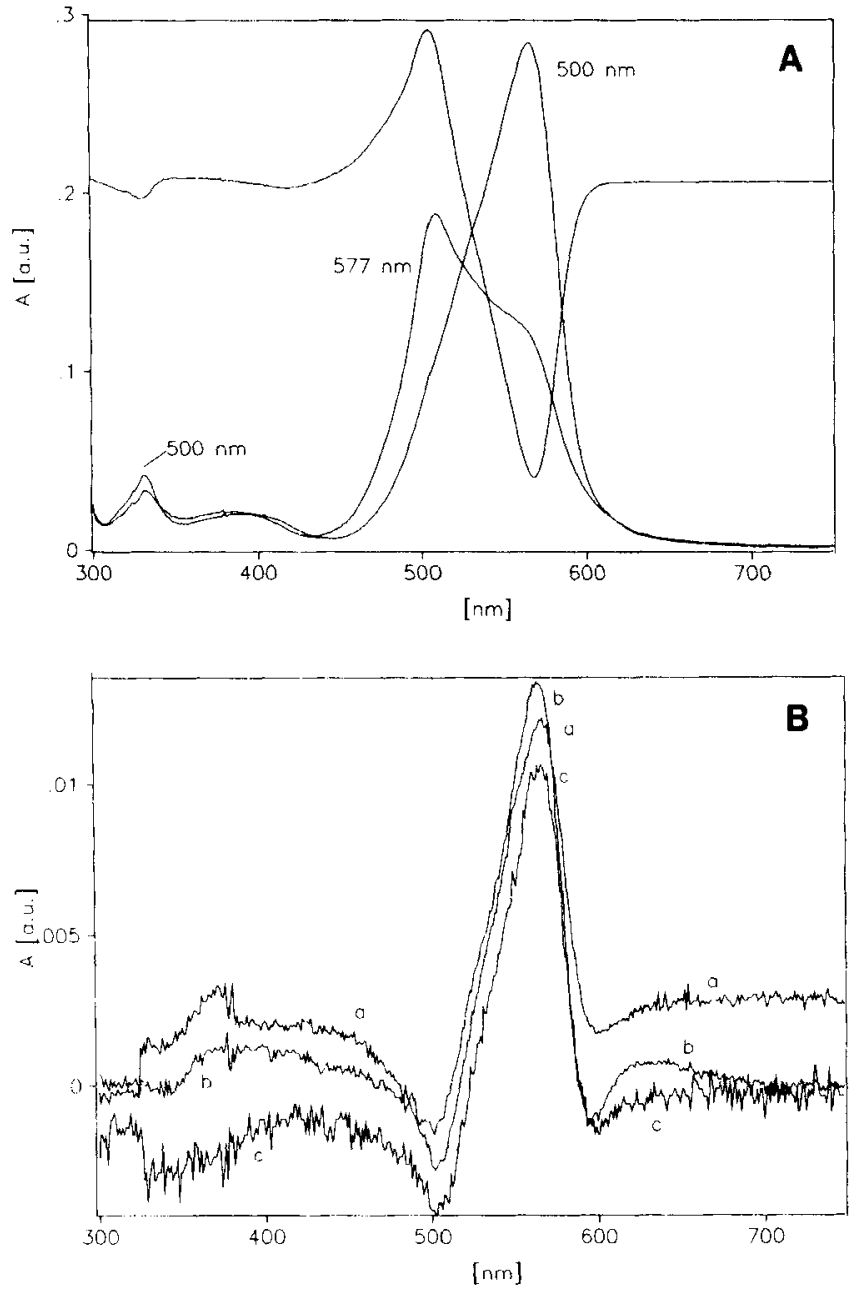

Figure 1. A) Type I photochemistry of PEC $\alpha$-subunit ("high-photochemistry sample", $\Delta \Delta A_{I}=92 \%$ ). Absorption spectra after saturating preirradiations with 500 and $577 \mathrm{~nm}$ light (see label). The upper curve is the difference spectrum on the same scale $(577 \mathrm{~nm}$ irradiated minus $500 \mathrm{~nm}$ irradiated). B) Type II photochemistry of PEC $\alpha$-subunit ("high-photochemistry sample"): Absorption difference spectra of three different isolates, which were first irradiated with $577 \mathrm{~nm}$ light, then with $600 \mathrm{~nm}$ light, and the spectra subtracted in that order. $\Delta \Delta \mathrm{A}_{1}$ of the type I $\left(\Delta \Delta \mathrm{A}_{\mathrm{II}}\right.$ of the type II) responses of the samples were a: $89(9.1)$, b: $91(5.3)$ and c: $49(7.8 \%)$.

as in the type I reaction. However, due to a modification in the protein, ${ }^{17}$ there may be a different interaction of the E-isomer with the environment. Since the spectral features of biliproteins are mainly determined by such interactions, ${ }^{16.19-}$ 22 this can lead to rather different spectra. An example for such interactions is $P_{\mathrm{fr}}$, which as an E-isomer absorbs at longer wavelengths than the $\mathrm{Z}$-isomer. ${ }^{26} \mathrm{~A}$ third, more exotic possibility would be the formation of another form of the Z-isomer by a process reminiscent of photophysical holeburning. The Z-E photoisomerization requires a considerable reaction volume and probably a certain amount of flexibility in the protein, ${ }^{16,19.20}$ and the quantitative variations of the type I photochemical signal have been related to changes in the rigidity of the apoprotein. The data presented here indicate that the type II photochemistry is not decreased in parallel, but rather remains unchanged or is even increased, ${ }^{17}$ thus indicating that the rigidity of the protein may play a 

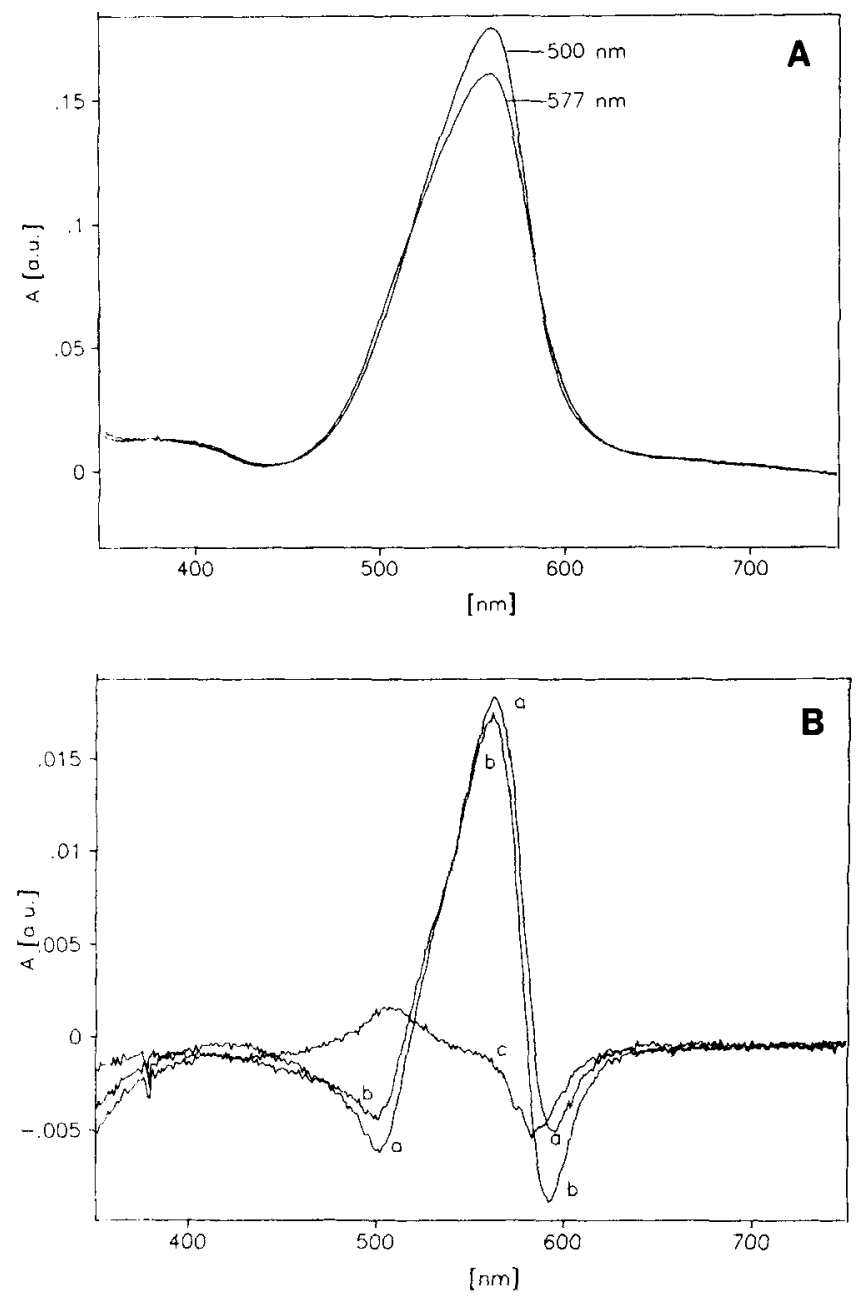

Figure 2. Photochemistry of PEC $\alpha$-subunit ("low-photochemistry sample"). A) Absorption spectra after saturating pre-irradiations with 500 and $577 \mathrm{~nm}$ light (see label). B) Absorption difference spectra for the following irradiation programs: a) 500 minus $577 \mathrm{~nm}$, b) 500 minus $600 \mathrm{~nm}$, c) 577 minus $600 \mathrm{~nm}$. Relative to the absorption spectra (A), the $y$-axis is expanded five fold.

lesser role. Line broadening is typical for photophysical holeburning, a process which is generally observed at low temperatures only. ${ }^{23}$ However, a protein has some structural features which might allow similar processes at ambient temperatures by locking the chromophores in local minima of the conformational space.

Acknowledgements - This work was supported by the Deutsche Forschungsgemeinschaft, Bonn (SFB 143, project A 1). K.-H.Z. acknowledges a postdoctoral stipend from the Alexander-von-Humboldt foundation, Bonn.

\section{REFERENCES}

1. MacColl, R. and D. Guard-Friar (1987) Phycobiliproteins, CRC Press, Boca Raton, FL.

2. Siebzehnrübl, S., R. Fischer, W. Kufer and H. Scheer (1989) Photochemistry of photobiliproteins: reciprocity of reversible photochemistry and aggregation in phycoerythrocyanin from Mastigocladus laminosus. Photochem. Photobiol. 49, 753-761.

3. Björn, G. S. (1979) Action spectra for in vivo and in vitro conversions of phycochrome $b$, a reversibly photochromic pigment in a blue-green alga, and its separation from other pigments. Physiol. Plant 46, 28!-286.

4. Kufer, W. and G. S. Björn (1989) Photochromism of the cyanobacterial light harvesting biliprotein phycoerythrocyanin. Physiol. Plant 75, 389-394.

5. Maruthi Sai, P. S., S. Siebzehnrübl, S. Mahajan and H. Scheer (1992) Phycoerythrocyanins from Westiellopsis prolifica and Nostoc rivulare: Characterization of the phycoviolobilin chromophore in both states. Photochem. Photobiol. 55, 119-124.

6. Kufer, W. (1988) Concerning the relationship of light harvesting biliproteins to phycochromes in cyanobacteria. In Photosynthetic Light Harvesting Systems (Edited by H. Scheer and S. Schneider), pp. 89-93. W. De Gruyter, Berlin.

7. Siebzehnrübl, S. (1990) Chromophorzuordnung und reversible Photochemie von C-Phycocyaninen und Phycoerythrocyaninen, Dissertation, Universität München.

8. Björn, G. S., N. Ekelund and L. O. Björn (1984) Light-induced linear dichroism in photoreversibly photochromic sensor pigments. 4. Lack of chromophore rotation in phycochrome-B immobilized in vitro. Physiol. Plant 60, 253-256.

9. Bishop, J. E., H. Rapoport, A. V. Klotz, C. F. Chan, A. N. Glazer, P. Füglistaller and H. Zuber (1987) Chromopeptides from phycoerythrocyanin. Structure and linkage of the three bilin groups. J. Am. Chem. Soc. 109, 875-881.

10. Dürring, M., R. Huber, W. Bode, R. Rümbeli and H. Zuber (1990) Refined three-dimensional structure of phycoerythrocyanin from the cyanobacterium Mastigocladus laminosus at 2.7 A. J. Mol. Biol. 211, 633-644.

11. Bryant, D. A. (1982) Phycoerythrocyanin and phycoerythrinproperties and occurrence in cyanobacteria. J. Gen. Microbiol. 128, 835-844.

12. Füglistaller, P., F. Suter and H. Zuber (1983) The complete amino-acid-sequence of both subunits of phycoerythrocyanin from the thermophilic cyanobacterium Mastigocladus laminosus. Hoppe Seyler's 2. Physiol. Chem. 364, 691-712.

13. Gantt, E. (1986) Phycobilisomes. In Photosynthesis 11I-Photosynthetic Membranes and Light Harvesting Systems (Edited by L. A. Staehelin and C. J. Arntzen), pp. 260-268. Springer, Berlin.

14. Braune, W., T. Wilczok and R. Waclawek (1988) Indications for photoreversible reactions in the range of Phycochrome $b$ absorption obtained by automated microscopic image analysis of germinating Anabaena akinetes. Cytobios. 54, 39-48.

15. Björn, L. O. (1979) Photoreversibly photochromic pigments in organism: properties and role in physiological ligth perception. Quart. Rev. Biophys. 12, 1-25.

16. Rüdiger, W. and F. Thümmler (1991) Phytochrome, the visual pigment of plants. Angew. Chem. Int. Ed. Engl. 30, 1216-1228.

17. Zhao, K.-H., Q. Hong, S. Siebzehnrübl and H. Scheer (1993) Phycoerythrocyanin: A pigment with two faces. In Frontiers of Photobiology (Edited by A. Shima, M. Ichihashi, Y. Fujiwara and H. Takebe), pp. 31-36. Elsevier, Amsterdam.

18. Falk, H. (1989) The Chemistry of Linear Oligopyrroles and Bile Pigments. Wien, Springer, New York.

19. Braslavsky, S. E., A. R. Holzwarth and K. Schaffner (1983) Konformationsanalyse, Photophysik und Photochemie der Gallenpigmente; Bilirubin-und Biliverdinmethylester und verwandte lineare Tetrapyrole. Angew. Chem. 91, 670-689; Angew. Chem. Int. Ed. Engl. 22, 656-674

20. Scheer, H. (1981) Biliproteine. Angew. Chem. 93, 230-250; Angew. Chem. Int. Ed. 20, 241-261.

21. Scheer, H. (1982) Light reaction path of photosynthesis. In Phycobiliproteins: Molecular Aspects of Photosynthetic Antenna Systems (Edited by F. K. Fong), pp. 7-45. Springer, Berlin.

22. Huber, R., M. Schneider, O. Epp, I. Mayr, A. Messerschmidt, J. Pflugrath and H. Kayser (1987) Crystallization, crystal structure analysis and preliminary molecular model of the bilin binding protein from the insect Pieris brassicae. J. Mol. Biol. 195, 423-434.

23. Friedrich, J. and D. Haarer (1984) Photochemical hole-burning and optical relaxation spectroscopy in polymers and glasses. Angew. Chem. 96, 96-123; Angew. Chem. Int. Ed. Engl. 23, 113-140. 